\title{
A Tale of Three Cities: Fostering Intrinsic Motivation for Information Seeking in Children of Diverse Cultures
}

\author{
Sherry R. Crow ${ }^{1} \&$ Lisa Kastello ${ }^{2}$ \\ ${ }^{1}$ College of Education, University of Nebraska Kearney, Kearney, Nebraska, USA \\ ${ }^{2}$ Bagwell College of Education, Kennesaw State University, Kennesaw, Georgia, USA \\ Correspondence: Sherry R. Crow, College of Education, University of Nebraska Kearney, Kearney, NE, USA. \\ Tel: 308-224-1552. E-mail: crowsr@unk.edu
}

Received: December 2, 2016

Accepted: January 18, 2017

Online Published: April 29, 2017

doi:10.5539/ies.v10n5p157

URL: https://doi.org/10.5539/ies.v10n5p157

\begin{abstract}
The purpose of the research was to increase understanding of the experiences in the lives of upper elementary-aged students that foster an intrinsic motivation to seek information, as well as to compare and contrast the experiences of intrinsically motivated students from an individualist culture (Colorado Springs, Colorado, U.S.), a collectivist culture (Kampala, Uganda) and a culture that is both individualistic and collectivist (Mysore, India). The principal results are that the informants from all three groups had an affinity for play, a tendency toward creativity, and that they enjoyed doing competence-building activities. A point of disparity in the findings was in the information seeking behavior of the collectivist Kampalan students with regard to their penchant for seeking information by asking other people as compared with the two less-collectivist groups. Interest/relevance was the dominant factor in all three groups of students' favorite information seeking quests. Major conclusions are that social conditions supporting all three needs (autonomy, competence, and relatedness) that foster intrinsic motivation were evident in the lives of the students, though relatedness and autonomy needs were balanced differently depending on their cultures. Recommendations based on this research for elementary school teachers and librarians are: to allow choice when possible, to provide creative alternatives for students to present information, to be sensitive to the differing relational needs of children, and to be there as a stable influence when immigrant students find circumstances overwhelming. Findings on the information-seeking styles by media types of the three sets of informants are included.
\end{abstract}

Keywords: collectivist cultures, cultural influences, education, elementary students, individualistic cultures, information seeking, information-seeking behavior, intrinsic motivation

\section{Introduction}

The population of children in American public schools today is more diverse than it was fifty, thirty, or even ten years ago. In fact, the 2014-2015 school year would mark a non-majority of white students (49.8\%) for the first time, a percentage expected to drop to $45.1 \%$ by 2023 (projection by National Center for Education Statistics [NCES], 2013). Much of the increase of non-white students comes from recent immigration. During 2013 and 2014, the foreign-born population in the U.S. increased by 1 million, with the number of immigrants reaching approximately 81 million, or 26 percent of the U.S. population (United States Census Bureau, 2016). Children of many lands and cultural backgrounds are changing the American classroom.

While the student population is becoming more diverse, the population of American teachers is still overwhelmingly homogeneous, at $82 \%$ Caucasian (NCES, 2013). Such disparity can strain teachers' capacity to understand the needs of their students, therefore decreasing their ability meet those needs. The reality is, whatever their race or ethnicity, teachers who do not understand the cultural backgrounds of their students may not be as effective as they could be in teaching them.

Learning more about the individuals who make up their classrooms can affect many aspects of teaching, not the least of which is how to motivate students to do their best. Motivating students is more than doing a pep talk or using gold stars and other external motivators. It is intrinsic motivation or "the inherent tendency to seek out novelty and challenges, to extend and exercise one's capacities, to explore and to learn" (Ryan \& Deci, 2000) that propels students into independent thinking and learning. 
The focus of this article is on the intrinsic motivation students have for information seeking, defined as "a conscious effort to acquire information in response to a need or gap in [one's] knowledge" (Case, 2002). As many elementary and middle school teachers and librarians know, the basic building block for students' success in developing intrinsic motivation for information seeking is the desire to pursue answers to their own questions, and studies seem to indicate that children's culture and social context, both in school and at home, can affect this all-important inner motivation (e.g., Chirkov \& Ryan, 2001; Crow, 2015; Crow \& Kastello, 2016).

\subsection{Purpose and Research Questions}

In an effort to increase understanding of the experiences in the lives of upper elementary-aged students that foster an intrinsic motivation to seek information, as well as to increase understanding of the cultural influences on students' intrinsic motivation to seek information, the authors conducted research with groups of children from three different cultural backgrounds: Colorado Springs, Colorado; Kampala, Uganda; and Mysore, India. The primary research question was "What are the experiences in the lives of upper elementary-aged students under study that foster an intrinsic motivation to seek information?" The secondary question was, "how do the experiences of these intrinsically motivated students from an individualist culture (U.S.), a collectivist culture (Uganda) and a culture that is both individualistic and collectivist (India) compare and contrast?"

\subsection{Theoretical Framework}

The framework focused on the experiences within the students' social milieu that either contributed to or detracted from their intrinsic motivation to seek information. The foundation was provided by the Self-determination Theory (SDT; Deci, \& Ryan, 1985). SDT is a motivational theory that conceptualizes three categories of motivation: amotivation, extrinsic motivation, and intrinsic motivation. Of particular interest to the studies were SDT's subtheories: Cognitive Evaluation Theory and Organismic Integration Theory.

Cognitive Evaluation Theory within SDT suggests that social contexts that produce a sense of autonomy and feelings of competence foster one's inherent tendency toward intrinsic motivation. Relatedness has also been found to be a significant factor (Ryan \& Deci, 2000). Autonomy means acting on one's own volition. (Ryan \& Deci, 2000). The need for competence is defined as "the need to experience oneself as capable of producing desired outcomes and avoiding negative outcomes" (Connell \& Wellborn, 1991, p. 51). Social conditions and contexts that enhance a perceived sense of competence for a task promote intrinsic motivation for that task (Ryan $\&$ Deci, 2000). The need for relatedness "encompasses the need to feel securely connected to the social surround and the need to experience oneself as worthy and capable of love and respect" (Connell \& Wellborn, 1991, pp. 51-52). SDT proposes that the needs for competence and autonomy are the most predominant in promoting intrinsic motivation, and that relatedness is also a substantial influence. Studies indicate that needing to belong, or desiring interpersonal connections, is a primary human need (Baumeister \& Leary, 1995).

Organismic Integration Theory (OIT) within SDT differentiates types of extrinsic motivation, providing a structure for studying social environments that "promote or hinder internalization and integration of the regulation for these behaviors" (Ryan \& Deci, 2000, p. 72). In OIT, the motivation types are not indicated as dichotomous. Rather, extrinsic motivation is a part of a continuum of behaviors fitted between amotivation and intrinsic motivation (see Figure 1).

Behavior Nonself-Determined $\quad$ Self-Determined

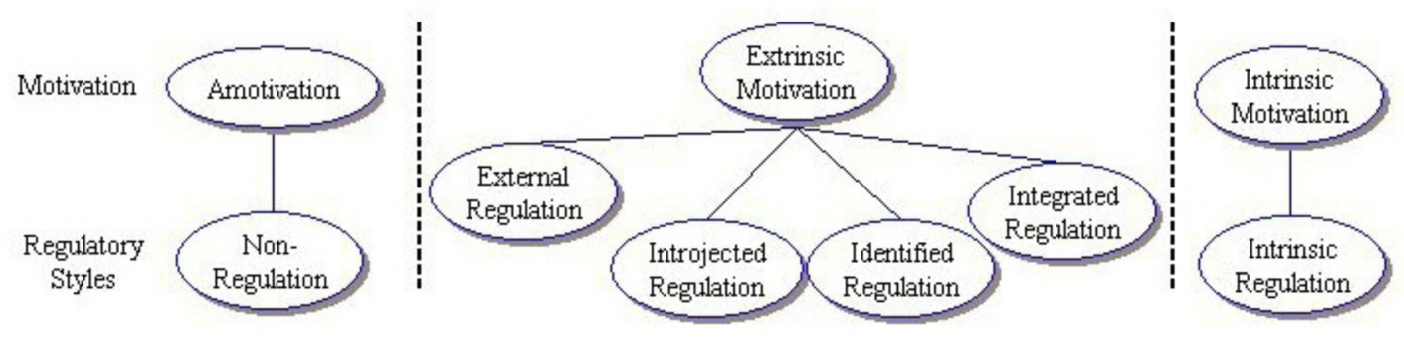

Figure 1. The self-determination continuum

From "Self-determination theory and the facilitation of intrinsic motivation, social development, and well-being," by D. L. Deci and R. M. Ryan, 2000, American Psychologist, 55(1), p. 72. Copyright (C 2000 by the American Psychological Association. 
The autonomy level perceived by an individual in a particular situation is the determining factor between the types of motivation and regulatory styles. In amotivation, people do not act at all or act without intent. Intrinsic motivation, on the other hand, emanates from the self and action is stimulated by interest, enjoyment, curiosity, or pleasure (Ryan \& Deci, 2000). The middle category, extrinsic motivation, is divided into four types. The first type, external regulation, consists of behaviors caused by an external demand or reward and is the least autonomous type of extrinsic motivation. The second type, introjected regulation, is action caused by a sense of pressure and is performed to enhance ego, pride, or self-worth, or to avoid guilt or anxiety. The third type, identified regulation, is a more autonomous type of extrinsic motivation, caused when one attaches personal importance to a behavior, generally modeled after the behavior of someone admired by the individual. The fourth type, integrated regulation, develops when behaviors founded on values are wholly assimilated (Ryan \& Deci, 2000).

\subsection{Cultural Framework}

A key postulate of SDT is that the three psychological needs of autonomy, competence, and relatedness are universal. Yet, in examining the three needs, there seems to be a tensity between autonomy (an individual's will or volition) and relatedness (community with other individuals). Heine, Lehman, Markus, and Kitayama (1999) proposed that persons living in individualistic cultures require more autonomy support, and that people affiliated with collectivist cultures need more satisfaction of their relatedness needs. However, several studies support the universality of autonomous-based motivation across cultures (Chirkov \& Ryan, 2001; Chirkov, Ryan, Kim, \& Kaplan, 2003; Grouzet, Otis, and Pelletier, 2006; Roth, Asor, Kanat-Maymon, and Kaplan, 2006). Moreover, research has shown that educational approaches that support students' autonomy have proven to be successful in highly collectivist cultures (Vansteenkiste, et al., 2005; Jang et al., 2009), suggesting that strategies fostering intrinsic motivation benefit people of all cultures (Chirkov, 2009).

\section{Methods}

\subsection{Participants}

The groups studied included students aged 10-12 in Colorado Springs, CO (primarily Caucasian, middle class, from various family configurations) in Kampala, Uganda (African, high poverty, orphaned), and in Mysore, India (high poverty, intact families). The three population areas were chosen based on the degree of individualism/collectivism of the three cultures as determined by the Hofstede-Bond Cultural Dimensions Scale (Hofstede Center, 2014; Rarick, et al., 2013), which describes the United States as primarily individualistic, Uganda as collectivist, and India as both individualistic and collectivist.

\subsection{Instrument for Identifying Study Participants}

The studies began by determining which of the children under study in the three populations had a high and distinct motivation for seeking information. This was done through administration of the Self-Regulation Questionnaire for Information Seeking (SRQ-IS, Crow, 2015). The SRQ-IS is a questionnaire that was adapted from the Academic Self-Regulation Questionnaire (SRQ-A), a similar instrument used with children to identify motivational regulation in academics (Ryan and Connell 1989). The questionnaire was administered by the researchers to all three groups of children who had parental permission [or the school's, in the case of the Ugandan children] in four fifth grade classrooms in Colorado Springs [100 students], with students above nine years of age at a school for orphans in Kampala [31 students] and in eight intermediate classrooms in Mysore [112 students]).The questionnaire was administered orally to students, making sure they were all on the same question throughout. In Kampala and Mysore, an interpreter in the common language of the students was also used (though many understood English). Through the questionnaire, students identified as being dominant for intrinsic motivation for information seeking, with at least a .03 differential between their highest and next highest motivational style, were determined to be the subjects ( 9 in Colorado Springs, 5 in Kampala, 16 in Mysore, See Figure 2). 


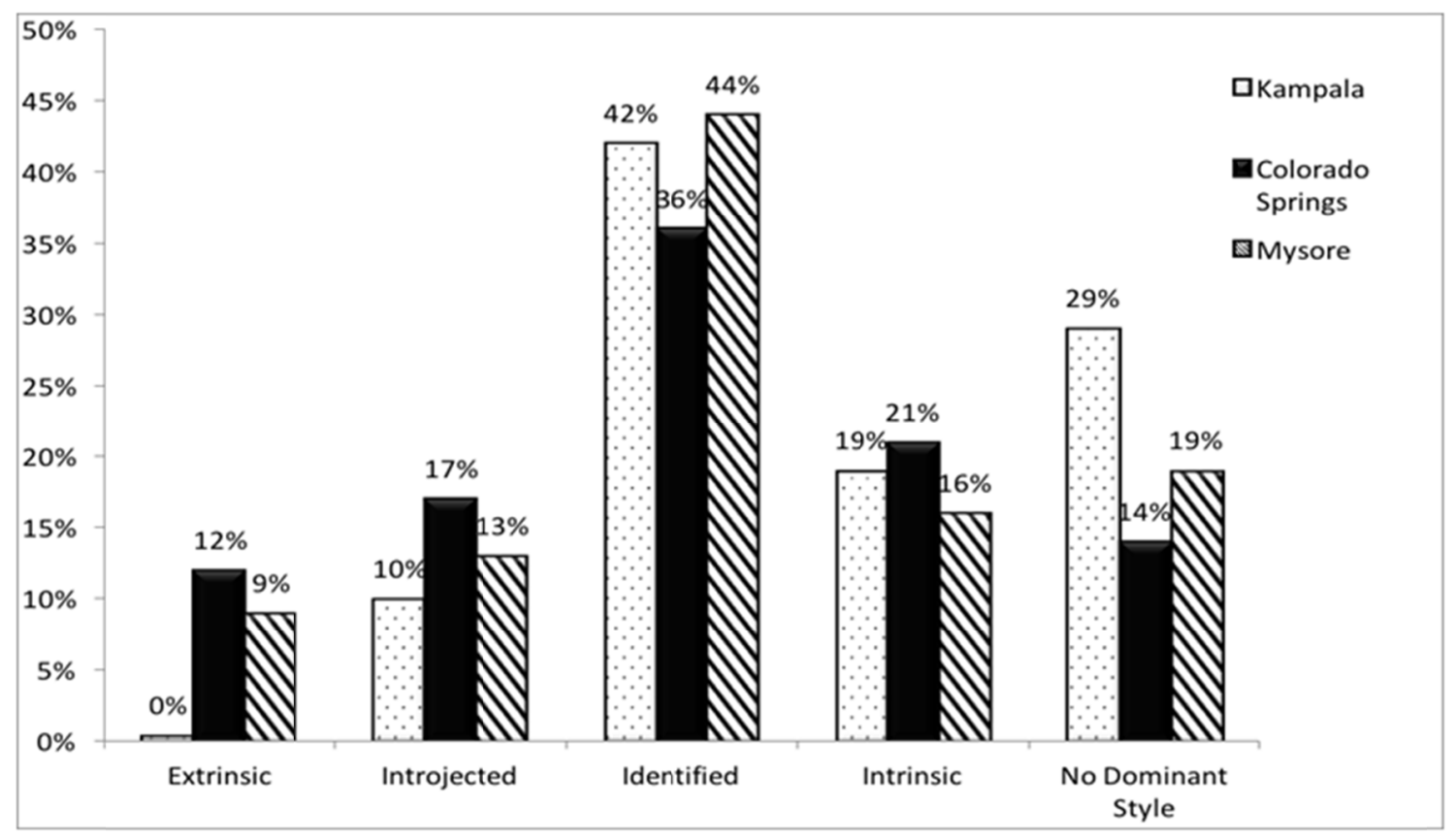

Figure 2. Dominant motivation styles of students in the Mysore, Kampala, and Colorado springs studies

Other interesting data gleaned from the survey were the consistency of the pattern of motivational styles in all three groups, with identified motivation ranking highest, followed by intrinsic, introjected, and extrinsic. "No Dominant Style" was found to be the highest in the Kampalan group, possibly due fact that these students were not used to making individual decisions as was required for this questionnaire.

\subsection{Data Collection}

All identified children were interviewed using semi-structured and open-ended questions, generally about their daily lives and specifically about their information seeking experiences, and also participated in a drawing activity on the same topics. The drawing activity provided an additional way students could express their answers, and served as a cross-check of the interviews. The researchers also observed classroom activity and interviewed the subjects' teachers and librarians.

\section{Results}

The findings revealed that the informants from all three groups had an affinity for play, a tendency toward creativity, and that they enjoyed doing competence-building activities.

\subsection{Play}

The Kampalan students were enthusiastic about play, especially organized team sports. During their free time at school, most boys played soccer and most girls played dodgeball. Winning and losing did not seem to enhance or dampen their enjoyment, as expressed by John when asked why he likes soccer even when he loses, "I just enjoy it. I love soccer so much." Outdoor group activities were predominant, but the children also mentioned individual activities such as skipping rope, swinging, racing, and riding bicycles, though they mostly did these activities with others rather than alone. Imaginative play was only mentioned by one child, who described in elaborate detail her pretend set of cooking utensils make from mud.

The children from Colorado Springs also mentioned sports, but not as often as the Kampalan students. Instead, they preferred biking, hiking, and photography. The Coloradoans also mentioned video games and other individual computer play, in which they engaged both alone and with friends. These children also exhibited a playful sense of humor, and mentioned that they often looked for books and movies that are funny and even chose their favorite teachers and playmates based on their level of "funniness."

The children from Mysore talked of play primarily along the theme of activities related to birthdays, religious holidays, and school-sponsored celebrations, (called "functions"). They especially mentioned singing, dancing, and storytelling. The researchers were able to observe a school function in which all of the children participated in at least one group of dancers. The practices beforehand went on for several days, resulting in performances 
that were quite polished for the age group. Brightly colored, well-made costumes added to the celebration despite the low-income status of the families involved. The Mysore informants also mentioned video and car games (though always with friends), and group games such as "hide and seek." This group of students did not mention playing alone.

\subsection{Creativity}

Creativity, "the tendency to generate or recognize ideas, alternatives, or possibilities that may be useful in solving problems, communicating with others, and entertaining ourselves and others" (Franken, 1994, p. 396) was a characteristic of all three groups of informants, though less so in the Kampalan students than the others. The children from Colorado Springs enjoyed writing in personal journals, creating books, and building websites, whereas the children from Mysore preferred drawing and often talked of parents and siblings helping them learn how to draw. All three populations showed a preference for choice in materials and subjects when expressing their creativity, and often pursued information on topics of interest that manifested in artistic creations, some as complicated as a website on extreme sports (Colorado Springs) and others as simple as a tea set formed of mud and clay (Kampala).

\subsection{Competence and Building Competence}

The Colorado Springs and Mysore children preferred doing activities for which they had exceptional knowledge or skill, such as math and drawing. Both sets of informants described many areas of knowledge and skills in which they felt competent and indicated that they participated in these areas because they felt smart or good at them. The Kampalan children, however, showed more determination at getting better at activities for which they had little skill - in particular school subjects - readily accepting informational feedback from teachers and community members alike. This attitude may have developed from both the need and will to survive in a harsh environment. Indeed, Starko posits that courage and persistence are among the characteristics that develop creativity in individuals (2014).

\subsection{Information-Seeking Experiences}

The information gleaned on the information-seeking behavior of the three groups of students was gathered from two questions, and their follow-up inquiries: 1) "What makes a good (happy) day for you?" and 2) "Tell me about a time when you sought information." The topics overlapped between the two questions, helping to affirm the informants as intrinsically motivated for information seeking as identified through the survey. Many of the questions from the three groups of students were similar, and involved the same topics such as animals, science, play activities, and general exploration. The following are sample inquiries posed by children from the three culture groups:

Whenever I'm like wandering in my mind when I have to ask information about nature and stuff. . .like, what would a regular spruce tree do in the summertime? Would it change colors? What kind of pine cones will it have? (Colorado Springs)

I like learning, but I mean it gets kind of boring sometimes, but researching stuff is like the best, doing projects. Holy cow, that's really fun. (Colorado Springs)

I like learning about soil, the division between soil and water. When it rains, I go down to the river bank and watch. (Kampala)

Our teacher was talking about Bikram and Betaal [from a folktale]. I wanted to know what was this story all about? My teacher said, "I'm not going to disclose anything, I'm not going to tell you anything. Go and find out yourself." (Mysore)

The influence of culture seemed to particularly impact students' information seeking experiences. The percentage of students who mentioned using books to find information was similar in all three groups (Colorado Springs 23\%, Kampala 18\%, and Mysore 18\%), as was the percentage of observers (Colorado Springs 13\%, Kampala 18\%, and Mysore 20\%), but the percentage of students who asked people for information was higher in the collectivist culture of Kampala (45\%) compared with the mixed individualistic/collectivist culture of Mysore $(36 \%)$, and much higher when compared with the individualistic culture of Colorado Springs (9\%) (See Figures 3,4 , and 5). 


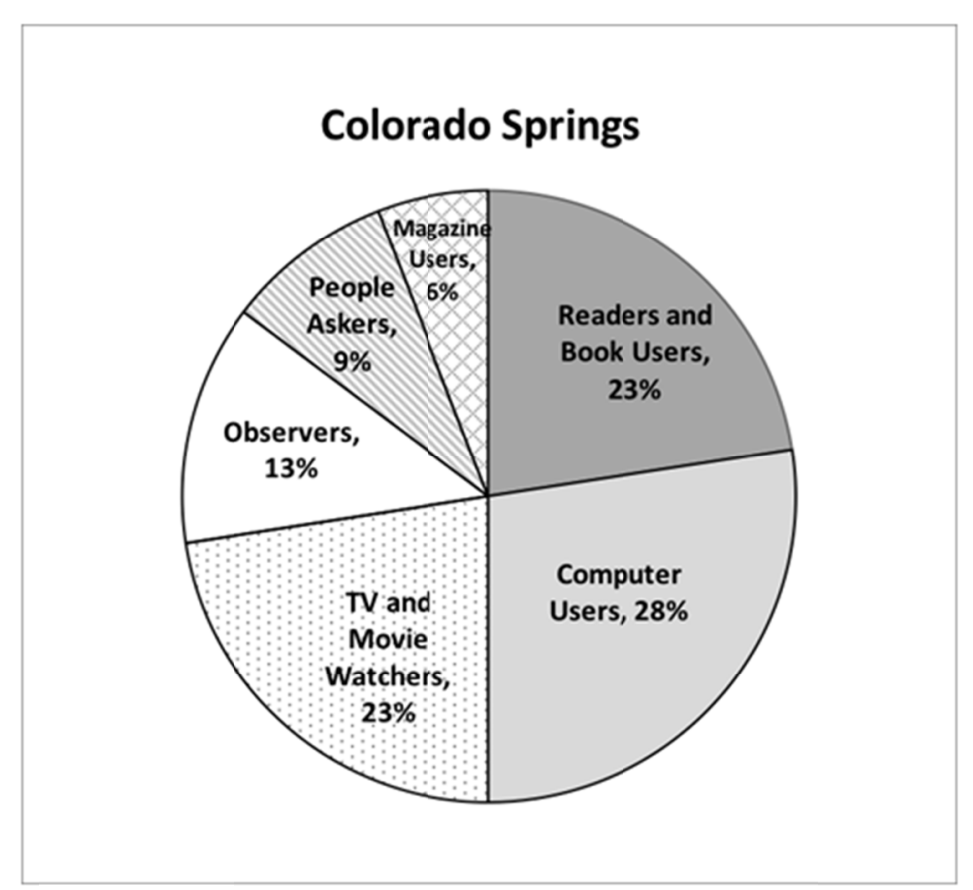

Figure 3. Colorado Springs students' information seeking styles by media types

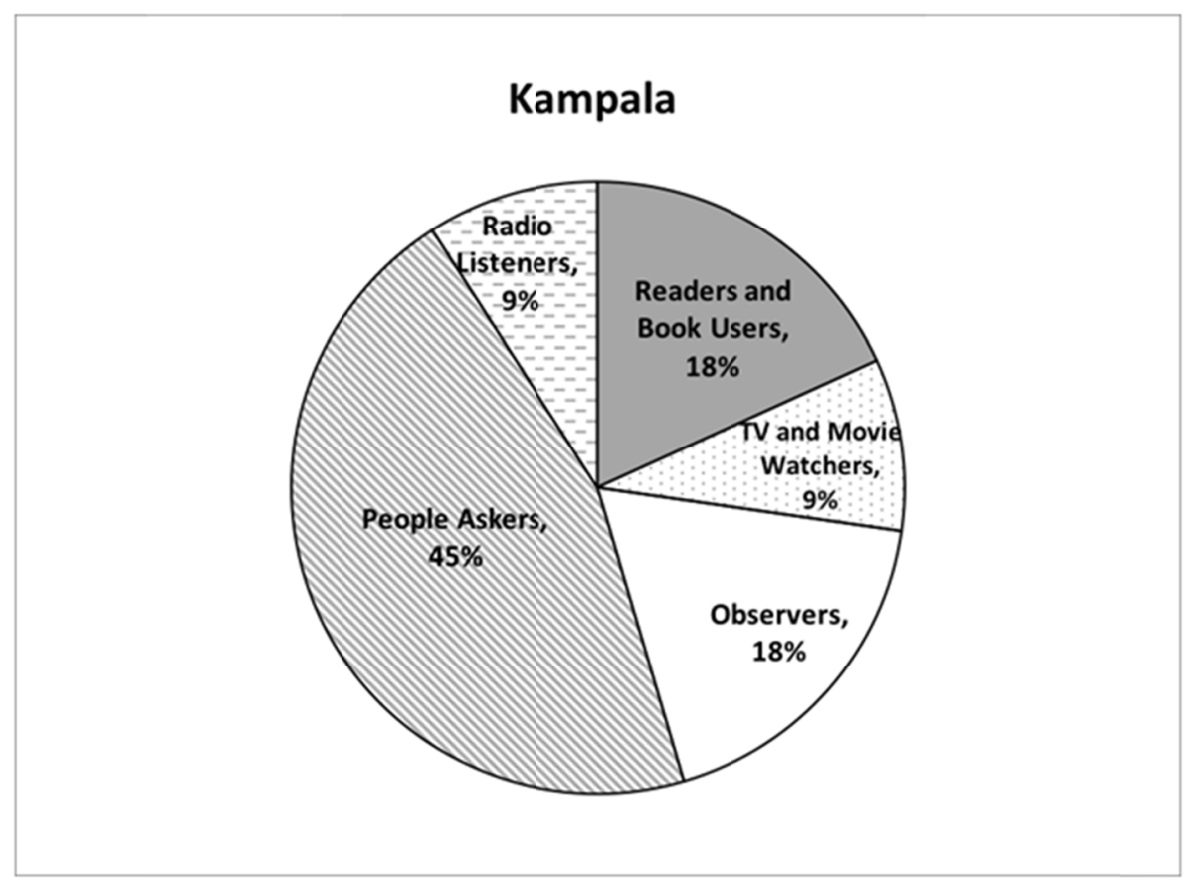

Figure 4. Kampalan students' information seeking styles by media types 


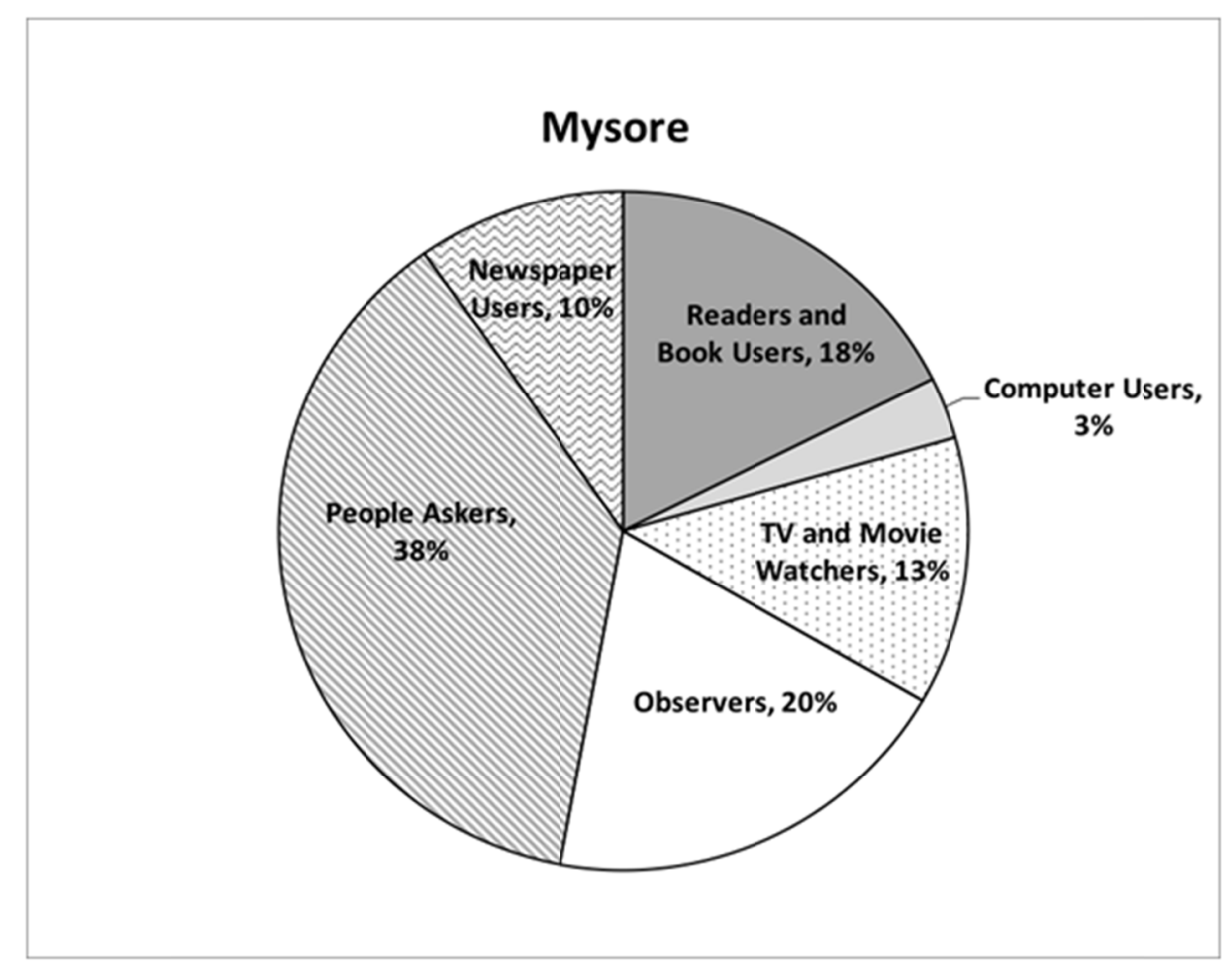

Figure 5. Mysore students' information seeking styles by media type

The children in all three groups were asked to describe two information seeking experiences, then choose their favorite of the two and explain why they chose it. Interestingly, all three groups of students gave interest/relevance of the topic more than any other answer.

\section{Discussion}

Analysis of the findings was conducted by the researchers, who maintained flexibility based on the informants' reactions and contributions. Social conditions supporting all three needs (autonomy, competence, and relatedness) that foster intrinsic motivation (Deci \& Ryan, 1985) were evident in the lives of the students, though relatedness and autonomy needs were balanced differently based on their cultures. All of the students thrived on play, a state that naturally supports children's autonomy, giving children the ability to direct their own worlds. More of the play of the children from Kampala and Mysore was conducted in groups as compared with the children of Colorado Springs (who seemed to prefer more solitary activities), suggesting that relatedness was embedded in the day-to-day activities of these children of predominantly collectivist (Kampala), and mixed collectivist/individualistic (Mysore) cultures. The creative nature of all of the informants points to desire for individual expression (autonomy), regardless of the collectivist bent of their societies. Perhaps the biggest point of disparity in the findings was in the information seeking behavior of the collectivist Kampalan students with regard to their penchant for seeking information by asking other people as compared with the two less-collectivist groups. Interest/relevance was the dominant factor in all three groups of students' favorite information seeking quests, pointing to the need for choice (autonomy) in topic selection. Finally, the desires of the children in Colorado Springs and Mysore to use their established abilities show realization of their competencies. In contrast, the determination of the Kampalans to improve their academic skills may show an understanding of the importance of building competence in these skills in order to survive.

The information gleaned was about individuals; children from three separate cultures who scored differentially high on a survey designed to measure intrinsic motivation for information seeking, and who were given a chance to share their experiences with researchers. It is important to keep in mind that findings revealed here are germane only to these specific groups of students; however, an understanding of their cultural influences may illuminate an understanding of the cultural influences of other students coming from similar backgrounds, as well as how social contexts in general influence intrinsic motivation for information seeking. 


\section{Applications and Recommendations}

\subsection{Allow Choice}

Regardless of culture, students enjoy choosing the topics they explore as well as the media through which they find their answers. Whenever possible allow students to answer their own questions rather than those posed by the educator. Encourage them to use a variety of sources even if they aren't conventional, such as interviewing/emailing an expert or going to a museum or zoo for answers.

\subsection{Provide Creative Alternatives}

While many teachers and librarians have moved into the technological world by encouraging alternative means of presenting information (such as Prezi, Weebly, or social media), there are many other ways of presenting information that are available to all children. Drawing, acting, molding clay, and writing songs are all ways that may be more accessible to children who are struggling with language skills, or who simply don't express themselves well with words. If possible, get the art and music teachers involved in research projects.

\subsection{Be Sensitive to Differing Relationship Needs}

For some children, going to school is the first and only thing they have ever done without their families. In both Kampala and in Mysore, the school students sat at long benches together rather than in individual desks. Students from collectivist cultures generally do better when working with a partner or in a group, especially if they are coming from classrooms set up this way. Conversely, students from individualistic cultures may prefer to work alone than to be forced to work in a group. Provide for different grouping configurations and allow students to choose their preferences, if not every time then at least occasionally.

\subsection{Be There when the Going Gets Tough}

Many students in our schools today are coming from difficult refugee situations or war-torn environments where simple existence was paramount. Though many of these children are behind in academics according to our schools' standards, they are far ahead in life lessons of survival. Give respect for their experiences while gently showing them the usefulness of enhancing their information seeking skills, especially in practical ways that can impact their lives and the lives of their families. It may be best to help them catch up privately during class breaks or after school; and if time is a factor, help them connect with a tutor or elder friend. Applaud their courage and persistence in doing better. Give these students the chance to show off their leadership skills whenever possible.

\section{Final Thoughts}

Educators cannot change their cultural heritage to better meet the needs of their students, nor would they want to. They can, however, intentionally learn more about their students' cultural backgrounds, individual needs, interests, and preferences. By using this knowledge, teachers help foster students' intrinsic motivation for information seeking in ways that work best for each individual, and thus guide them to bettering their lives in their own ways for their own reasons.

\section{Acknowledgments}

This study was funded in part through grants from the Research Services Council of the University of Nebraska Kearney. We are very grateful to the schools and children who participated in the study and to Gwen Giddens, Courtney and Chris Vaughn, Claire Kasande Atwooki, Edith Di Stefano, Deborah Sizer, Tim and Karla Shamala, and Sharath Kumar.

\section{References}

Baumeister, R., \& Leary, M. R. (1995). The need to belong: Desire for interpersonal attachments as a fundamental human motivation. Psychological Bulletin, 117(3), 497-529. http://dx.doi.org/10.1037/0033-2909.117.3.497

Case, D. O. (2002). Looking for information: A survey of research on information seeking, needs, and behavior. San Diego, CA: Academic Press, 2002.

Chirkov, V. I. (2009). A cross-cultural analysis of autonomy in education: A self-determination theory perspective. Theory and Research in Education 7 (2): 253-62. http://dx.doi.org/10.1177/1477878509104330

Chirkov, V. I., \& Ryan, R. M. (2001). Parent and teacher autonomy support in Russian and U. S. adolescents. Journal of Cross-Cultural Psychology, 32, 618-635. 
Chirkov, V. I., Ryan, R. M., Kim, Y., \& Kaplan, U. (2003). Differentiating autonomy from individualism and independence: A Self-determination theory perspective on internalization of cultural orientations and well-being. Journal of Personality and Social Psychology, 84(1), 97-110. http://dx.doi.org/10.1037/0022-3514.84.1.97

Connell, J. P., \& Wellborn, J. G. (1991). Competence, autonomy, and relatedness: A motivational analysis of self-system processes. In M. Gunnar, \& A. Sroufe (Eds.), Minnesota symposium on child psychology (Vol. 23., pp. 43-77). Hillsdale, NJ: Lawrence Erlbaum Associates.

Crow, S. R. (2015). The information-seeking behavior of intrinsically motivated elementary school children of a collectivist culture. School Library Research, 18. Retrieved from http://www.ala.org/aasl/sites/ala.org.aasl/files/content/aaslpubsandjournals/slr/vol18/SLR_InformationSeeki ngBehavior_V18.pdf

Crow, S. R., \& Kastello. (2016). The dispositions of elementary school children of individualistic and collectivist cultures who are intrinsically motivated to seek information. School Library Research, 19. Retrieved from http://www.ala.org/aasl/sites/ala.org.aasl/files/content/aaslpubsandjournals/slr/vol19/SLR_DispositionsofEl ementary_V19.pdf

Deci, E. L., \& Ryan, R. M. (1985). Intrinsic motivation and self-determination in human behavior. New York: Plenum Press.

Franken, R. E. (1994). Human motivation. Pacific Grove, CA: Brooks/Cole.

Grouzet, F. M. E., Otis, N., \& Pelletier, L. G. (2006). Longitudinal cross-gender factorial invariance of the academic motivation scale. Structural Equation Modeling, 13(1), 73-98. http://dx.doi.org/10.1207/s15328007sem1301_4

Heine, S. J., Lehman, D. R., Markus, H. R., \& Kitayama, S. (1999). Is there a universal need for positive self-regard? Psychological Review, 106, 766-794. http://dx.doi.org/10.1037/0033-295X.106.4.766

Hofstede Center (2014). Geert Hofstede: Cultural insights. Retrieved from http:/geert-hofstede.com/

Jang, H., Reeve, J., Ryan, R. M., \& Kim, A. (2009). Can self-determination theory explain what underlies the productive, satisfying learning experiences of collectivistically oriented Korean students? Journal of Educational Psychology, 101(3), 644-661. http://dx.doi.org/10.1037/a0014241

Rarick, C., Winter, G., Nickerson, I., Falk, G., Barczyk, C., \& Asea, P. K. (2013). An investigation of Ugandan cultural values and implications for managerial behavior. Global Journal of Management and Business Research, 13(9). Retrieved from http://journalofbusiness.org/index.php/GJMBR/article/view/1056

Roth, G., Asor, A., Kanat-Maymon, Y., \& Kaplan, H. (2006). Assessing the experience of autonomy in new cultures and contexts. Motivation and Emotion 30(4), 365-376. http://dx.doi.org/10.1007/s11031-006-9052-7

Ryan, R. M., \& Connell, J. P. (1989). Perceived locus of causality and internalization: Examining reasons for acting in two domains. Journal of Personality \& Social Psychology, 57, 749-61. http://dx.doi.org/10.1037/0022-3514.57.5.749

Ryan, R. M., \& Deci, E. L. (2000). Self-determination theory and the facilitation of intrinsic motivation, social $\begin{array}{llll}\text { development, and } \quad \text { american } & \text { Psychologist, } & \text { 55(1), } & \text { 68-78. }\end{array}$ http://dx.doi.org/10.1037/0003-066X.55.1.68

Starko, A. J. (2014). Creativity in the classroom: Schools of curious delight (5th ed.). New York: Routledge.

U. S. Department of Education, National Center for Education Statistics. (2013). Enrollment and percentage distribution of enrollment in public elementary and secondary schools, by racelethnicity and level of education: Fall 1998 through fall 2023. Retrieved from https://nces.ed.gov/programs/digest/d13/tables/dt13_203.60.asp?current=yes

U.S. Department of Education, National Center for Education Statistics. (2013). Characteristics of public and private elementary and secondary school teachers in the United States: Results from the 2011-12 schools and staffing survey. Retrieved from https://nces.ed.gov/fastfacts/display.asp?id=55

United States Census Bureau (2016). American community survey. Retrieved from https://www.census.gov/programs-surveys/acs/about.html

Vansteenkiste, M., Zhou, M., Lens, W., \& Soenens, B. (2005). Experiences of autonomy and control among 
Chinese learners: vitalizing or immobilizing? Journal of Educational Psychology, 97(3), 468-83. http://dx.doi.org/10.1037/0022-0663.97.3.468

\section{Copyrights}

Copyright for this article is retained by the author(s), with first publication rights granted to the journal.

This is an open-access article distributed under the terms and conditions of the Creative Commons Attribution license (http://creativecommons.org/licenses/by/4.0/). 